\title{
Comportamento do consumidor infantil: um estudo do consumo dos pais em supermercados através da influência dos filhos no momento da compra
}

\author{
Children consumer behavior: a study of parents' consumption in \\ supermarkets through the influence of children at time of purchase
}

Resumo

\author{
Marconi Freitas-da-Costa ${ }^{\mathrm{I}}$ \\ Raniere de França Lima ${ }^{2}$ \\ Paula Janaine dos Santos $^{3}$
}

Este estudo foi realizado com o objetivo de analisar os fatores relevantes do comportamento do consumidor infantil no momento das compras no supermercado e a influêncía que o público infantil exerce sobre os pais. Para tanto, foram aplicados 108 questionários do típo survey dirigido aos pais e para complementação foi feíto em paralelo um total de oíto horas de observação com 24 críanças no momento das compras. Os achados revelam que os fatores que têm maior poder de influêncía são: boa qualidade, boa divulgação e um preço acessivel, poís tiveram um alto grau de concordância por parte dos pais.

Palavras - chave: Marketing infantil; Supermercado; Compras.

\section{Abstract}

This study was realized with the objective of analyzing the relevant factors of child consumer behavior at the time of purchasing in supermarkets and the influence that this audience has on the parents. For getting the results, 108 Survey questionnaires were administered to the parents and to complement these results it was made in parallel a total of eight hours of observation with 24 children in the moment of purchase. The results show that all theories used in the research are important to the decision of that target audience and it can be conclude that the marketer must have thorough understanding of each factor that influences children at the time of purchasing, so they can perform work directed to this segment and get the desired success.

Keyword: Marketing to children; Supermarket; Purchases.

\footnotetext{
1 marconi_costa@hotmail.com, Brasil. Professor Assistente 2 da Universidade Federal de Pernambuco. Mestre em Administração pela UFPE. Rodovia BR 104, Km 59, s/n - 55016-630 - Caruaru, PE - Brasil.

2 raneflima@yahoo.com.br, Brasil. Graduando em Administração, Universidade Federal de Pernambuco - UFPE. Rodovia BR 104, Km 59, s/n - 55016-630 - Caruaru, PE - Brasil.

${ }^{3}$ paulajanaine@hotmail.com, Brasil. Graduanda em Administração Universidade Federal de Pernambuco - UFPE. Rodovia BR 104, Km 59, s/n - 55016-630 - Caruaru, PE - Brasil.
}

Recebido em 07.03.2012

Aprovado em 28.08.2012

Revista Administração em Diálogo ISSN 2178-0080

Programa de Estudos Pós-Graduados em Administração

Pontifícia Universidade Católica de São Paulo 


\section{Introdução}

A pesquisa realizada pela ABMN (Associação Brasileira de Marketing \& Negócios), conjuntamente com o IBOPE entre o segundo semestre de 2008 e o início de 2009, revelou que a atuação do marketing passou por muitas mudanças nos últimos anos e que a complexidade na estrutura das organizações em relação ao passado é um dos principais catalisadores deste processo (ABMN, 2009).

Com o resultado foi percebido diferentes configurações da estrutura de marketing nas empresas, uma dessas configurações é o marketing por segmento. A segmentação de mercado tende a dividir os grupos de consumidores em nichos cada vez menores, com o objetivo de estudar e conhecer um determinado grupo de clientes. A partir do momento que o mercado é composto por pessoas com diferentes necessidades e desejos, esse conhecimento se torna essencial para os profissionais de marketing.

Um dos campos que está em evidência é a área do marketing infantil, observações de diferentes autores alegam que o público infantil atinge cada vez mais rápido sua maturidade, inclusive a consciência do consumo. Assim tornando-os um grupo com grande potencial para o consumo. Analisar esse tipo específico de consumidor é fundamental para entendê-los, saber o que querem e quais as suas reações diante dos estímulos oferecidos. De acordo com McNeal (I992), a importância da criança como consumidora começa a crescer a partir da década de I950, decorrente do fenômeno do Baby Boom, que expandiu o número de crianças em 50\% nos Estados Unidos, somado à afluência econômica do país, que provocou uma transferência de renda dos pais para os filhos (MCNEAL, I969).

Uma das premissas fundamentais do moderno campo do comportamento do consumidor é a de que as pessoas frequentemente compram produtos não pelo que eles fazem, e sim, pelo que significam (SOLOMON, 2008). Isso se torna excepcionalmente verídico quando se trata de crianças, pois elas reconhecem facilmente personagens, o desenho simples, as cores vivas e expressivas das 
emoções atribuídas a eles, fazem dos personagens o porta-voz ideal da empresa para a criança.

É importante para os profissionais da área de marketing ter consciência dos desejos e necessidades do público infantil, pois como afirma McNeal (I992) a importância deste público se intensifica quando são levados em conta os diferentes papéis que a criança-consumidora assume: mercado primário (a criança pode ser um consumidor); mercado influenciador (a criança pode influenciar o consumo); e mercado futuro (a criança constitui um mercado potencial). Sendo assim esse público alvo demonstra sua importância para as organizações deste segmento. Portanto, a pesquisa tem como objetivo analisar o comportamento do consumidor infantil e como o marketing influencia esse público-alvo no momento das compras no supermercado.

\section{Revisão da Literatura}

A revisão da literatura a seguir buscou explorar os seguintes conceitos do consumo infantil, sob três perspectivas: (i) o processo de compra do público infantil; (ii) o mercado infantil; e (iii) fatores influenciadores do comportamento infantil.

\section{a. O Processo de Compra do Público Infantil}

A percepção das crianças é moldada pelo seu passado e por suas habilidades. Portanto o principal critério para essa segmentação do público infantil é por faixa etária. Para McNeal (1992) existe um processo de desenvolvimento da criança como consumidora que se inicia quando ela acompanha os pais ao supermercado e os observa: depois, acompanha-os e solicita produto/serviço, acompanha-os e seleciona bens e serviços sob permissão; acompanha-os e faz suas próprias compras de forma independente e por fim quando ela vai sozinha à loja e faz sua escolha e compra de forma independente.

As crianças acompanham seus pais ao local de compra a partir de I mês de idade e começam a efetuar compras independentemente a partir dos 4 anos, 
seguindo cinco estágios: Estágio I- observação (interação com o local, contato sensorial); Estágio 2- fazendo pedidos (o único estímulo é a vitrine, pede quando vê. Começam a pedir objetos desejados em suas casas, em especial quando as propagandas da TV se tornam estímulo significativo. A partir dos 2 anos já fazem pedidos e com 3 anos cerca de 2/3 fazem pedidos verbais); Estágio 3-Selecionando (Desenvolvem uma memória da loja e expressam o desejo de independência, localizando e retirando produtos que os satisfazem. O layout da loja, sua disposição e a embalagem do produto são de extrema importância para a criança); Estágio 4Efetuando compras com auxílio (ao receber algum dinheiro de seus pais, passa a entender que a loja aonde vai possui produtos e o dinheiro é o meio da permuta. Torna-se um consumidor primário que gasta seu dinheiro com suas próprias necessidades e desejos; apesar de existirem casos em que isto se realiza aos 2 anos, em média isto parece ocorrer aos 5 anos); Estágio 5- Efetuando compras com independência (realiza compras sem o auxílio dos pais. Algumas compram sem seus pais a partir de 4 anos, embora a idade média seja de 8 anos) (WHITE, I997).

Engel (2000) faz uma divisão em cinco estágios da criança como consumidor: observando, fazendo pedidos, fazendo seleções, fazendo compras assistidas e fazendo compras independentes. É Gade (I980) quem afirma, que a Influência do comportamento de compra infantil aumenta com a idade. As crianças também influenciam nas compras familiares fazendo suas próprias exigências em relação aos produtos pagos e comprados pelos pais. Em seguida, os filhos adolescentes começam a ter seu próprio dinheiro (mesada) e só através da mesma, é que eles se tornam pagantes e compradores de artigos para seu uso próprio, os filhos influenciam a escolha dos pais por produtos destinados ao consumo conjunto (por exemplo, férias familiares) ou mesmo produtos usados somente pelos pais.

Além da idade, Karsaklian (2000) afirma que há outros fatores que devem ser levados em consideração quando se fala em grau de influência da criança sobre os pais: quanto mais habituada a utilizar seu dinheiro para comprar seus produtos, mais abertura os pais lhe dão para intervir no processo de decisão, quanto mais 
elevada a classe social a qual pertence, mais influência ela terá na fase de reconhecimento do problema, as meninas têm maior influência que os meninos, principalmente na adolescência.

\section{b. O Mercado Infantil}

A partir da idade é possível estimar quanto uma empresa poderá lucrar ao longo da vida daquele cliente, ou seja, quanto ele gastará comprando seus produtos e serviços. Isso é chamado Ciclo de Vida do Cliente (SHETH; MITTAL; NEWMAN, 2OOI). No Brasil, a criança é a soberana do lar (GIACOMINI, I99I). Isso porque com a crescente participação da mulher no mercado de trabalho, os filhos ficam menos na presença dos pais e estes tentam compensar a falta cedendo a todos os desejos dos filhos, principalmente no que diz respeito ao consumo. Assim, a criança escolhe o que comer, vestir, entre outros artigos inclusive para os adultos da casa.

De acordo com McNeal (2000), 90\% das crianças vão às compras pelo menos uma vez ao mês com seus pais. No entanto, esse boom de produtos para as crianças pode ser prejudicial para elas, caso os pais não observem o que compram para os seus filhos.

A AcNielsen (2003), empresa no ramo de pesquisa, realizou um estudo sobre o panorama do mercado infantil brasileiro e constatou que o faturamento desse mercado infantil chegou a R $\$ 7$ bilhões. Foram analisados os produtos com apelo infantil de 47 categorias de produtos compostas pelas Cestas Higiene e Beleza, Mercearia Doce e Salgada, Perecíveis e Bebidas Não Alcoólicas.

O segmento infantil representa $22 \%$ do total da Cesta de Higiene e Beleza, que por sua vez é responsável por 2i\% do faturamento do mercado infantil. Analisando-se mais detalhadamente essa Cesta de Higiene e Beleza, percebe-se que os produtos infantis crescem em patamares superiores ao segmento adulto (ACNIELSEN, 2003). 
Karsaklian (200o) cita um resultado de pesquisas realizadas ilustrando elementos que sejam suscetíveis de desenvolver nas crianças atitudes positivas ou negativas em relação à propaganda, como descreve-se: a) as crianças desejam que a propaganda as divirta, se conseguir fazê-las rir, o primeiro obstáculo terá sido superado; b) as propagandas que utilizam a forma de desenho animado são apreciadas pelas crianças; c)uma boa música ou canção atraente costuma favorecer o interesse pela propaganda; d) além de contribuir para a memorização, a presença de jingles ou de frases de efeito reforçam o caráter positivo da atitude; e) a presença de animais, principalmente os personificados; f)propagandas ricas em ação, bem como, as que põem em evidência valore que são importantes para as crianças de cada idade (ser forte, ser inteligente, ser o bom amigo, ser o herói da turma); e g) os mais novos gostam de propagandas em que o protagonista é uma pessoa de idade (um vovô ou uma vovó).

Porém, além de saber quais os elementos que contribuem para o desenvolvimento de atitudes positivas, é necessário conhecer em que direção será conduzida a atitude da criança após seu primeiro contato com a propaganda. Esta idéia está diretamente relacionada com a repetição da propaganda. Segundo uma pesquisa realizada por Gorn e Goldberg (I980), a resistência das crianças à repetição de uma mesma propaganda é rejeitada após cinco exposições e os melhores escores de atitude positiva foram encontrados quando para um mesmo produto, as crianças eram expostas a várias propagandas diferentes.

A dificuldade da compreensão da reação das crianças com relação à propaganda, para os pesquisadores, vem do fato de esta relação ser extremamente afetiva. Derbaix (I975 e I982) foi um dos primeiros autores a pesquisar as consequências que poderiam acarretar a ênfase do elemento afetivo à resposta das crianças à comunicação publicitária. Seus estudos conduziram à criação de um novo modelo de hierarquia dos efeitos, o qual denominou de "modelo do envolvimento máximo’, ou ‘modelo da reação emocional', pois os já existentes não conseguiam explicar a total importância da dimensão emocional que guia o processo de consumo 
das crianças. Ao analisar os componentes: cognitivo, afetivo e conativo, o autor afirma que a primeira atitude da criança seria passar pelo atitudinal (afetivo), depois para o comportamental (conativo), sem muitas vezes conhecer o produto (cognitivo). Diz o autor: Na verdade, a criança primeiro deseja o produto, o adquire e somente depois o analisa a partir de sua própria utilização e mediante os comentários dos pais e amigos.

\section{c. Fatores Influenciadores do Comportamento Infantil}

O processo de consumo inicia-se com as expectativas que as pessoas têm sobre a vida que gostariam de levar, organizadas em torno de eixos centrais, como expectativas sobre uma nova vida, o corpo, as idéias, o outro, os objetos etc. E diante dessas expectativas o ser humano seleciona os estímulos que se relacionam com eles; este processo é chamado de percepção (GIGLIO, 2002).

Conforme Engel et al. (2000), processamento de informação refere-se ao processo pelo qual um estímulo é recebido, interpretado, armazenado na memória e mais tarde recuperado. Outro conhecimento que o profissional de Marketing precisa ter é de que este processamento de informação começa quando padrões de energia na força de entrada de estímulo alcançam um ou mais dos cincos sentidos. A exposição (primeiro estágio) ocorre em função da proximidade física a um estímulo que permita a oportunidade de que um ou mais sentidos sejam ativados. Isto exige que o gerente de produtos ou a área de Marketing da empresa selecione um meio de comunicação interpessoal ou de massa que alcance o mercado-alvo (ENGEL et al., 2000).

As crianças apresentam uma atração compulsiva por outros seres iguais, são capazes de interessar-se nos primeiros meses de vida em trocas sociais com os adultos que acercam, através dos sons, dos sorrisos e do choro. Se no início parecem apenas rituais, logo se tornam formas de comunicação sobre sentimentos, intenções, necessidades, medos que serão com certeza o ensaio para as comunicações verbais posteriores (GARDNER, I994). Outro fato de relevante importância 
como afirma Peter e Olson (I999) é que as crianças, nessa cultura de consumo transmitida diariamente, são estimuladas a compra e a posse como sinal de status.

As possibilidades de consumo da criança variam de acordo com suas diferentes fases de idade, conforme descrito por Le Bigot (I980) à medida que vão crescendo suas aptidões cognitivas e seus recursos financeiros irão se desenvolvendo, conduzindo a um efeito de sinergia e logo a uma ampliação da sua esfera de consumo. A socialização do consumidor infantil não se dá de forma independente. Conforme Brëe (I995) existem diversos agentes que a impactam (MCNEAL, I992; MOSCHIS; MOORE, r978), destacando-se o papel da família, da escola, dos amigos e da mídia de massa nesse processo (WHITE, I997).

Gade (I998) cita o caso de crianças que pedem determinados produtos aos seus pais não pelo seu próprio valor ou utilidade, mas como prova de atenção e de carinho. Esta necessidade social acaba influenciando o comportamento dos pais em relação ao consumo e, como vimos anteriormente, os faz ceder mais facilmente no ato da compra. Algumas pesquisas validam essa afirmação: i) Estatísticas mostram que pais de filhos separados tendem a consumir muito mais, pela competição dos pais que tentam comprar o afeto dos filhos (GADE, I998); 2) Um estudo da McCann-Erickson do Brasil indicou que $76 \%$ dos pais cedem quase sempre aos pedidos dos filhos no supermercado. Apenas $9 \%$ não se deixam levar por apelos infantis (PIRES, I995).

\section{Delineamento da Pesquisa}

A pesquisa é classificada como quantitativa, onde utiliza a coleta e a análise de dados para responder as questões de pesquisa e testar as hipóteses estabelecidas previamente, e confia na medição numérica, na contagem e frequentemente no uso de estatística para estabelecer com exatidão os padrões de comportamento de uma população (SAMPIERI; COLLADO; LUCIO, 2006).

Quanto aos fins, a pesquisa é descritiva, porque visa descrever o que influencia o consumidor infantil na hora de comprar. Segundo Gil (I995) a pesquisa 
descritiva tem como objetivo a descrição das características de determinada população ou fenômeno. Em relação aos meios, a pesquisa será bibliográfica e de campo. A pesquisa bibliográfica é o estudo sistematizado desenvolvido com base em materiais publicados em livros, artigos científicos, isto é, em material acessível ao público em geral (VERGARA, 2009). A pesquisa será de campo, porque foram coletados dados primários junto aos pais, e também houve a coleta através do método de observação, dirigido este as crianças. Foi usado o questionário do tipo survey para coletar os dados que segundo Malhotra (200I), survey é uma entrevista com um grande número de pessoas por meio de questionário predeterminado.

\section{Seleção da Amostra}

A população amostral ou amostra é uma parte da população (conjunto de elementos que possuem as características que serão objeto de estudo) escolhida segundo algum critério de representatividade (VERGARA, 2009). A amostra é um subconjunto pequeno da população, podendo ser probabilística ou não probabilística. Este artigo tem como base a amostra não probabilística onde confiase no julgamento pessoal do pesquisador, que arbitrária ou conscientemente, decide os elementos a serem incluídos na amostra (MALHOTRA, 2006). Em relação às técnicas da amostra não probabilística foi usada a amostra por conveniência, que segundo Malhotra (2006), procura obter uma amostra de elementos convenientes, onde a seleção é deixada a cargo do entrevistador. O processo de amostragem não probabilística por conveniência envolve a seleção de elementos da amostra que estejam mais disponíveis para tomar parte no estudo e que pode oferecer informações necessárias (GIL, I995).

A população amostral desta pesquisa foram pais com filhos na faixa etária de o a I2 anos. A realização da coleta dos dados foi mediante a aplicação de questionários surveys estruturados, com questões fechadas onde o respondente pode escolher entre um número determinado de respostas (HAIR Jr. et al., 2005). 
Foram aplicados Io8 questionários tipo survey com os pais, e foram observadas 24 crianças no supermercado.

\section{Coleta dos Dados}

Para melhor compreensão dos fatores que influenciam o público infantil no momento das compras no supermercado, a pesquisa foi realizada em duas etapas. $\mathrm{Na}$ primeira foi utilizado o método da observação com as crianças e na segunda foi realizado um questionário tipo survey com pais que tinham filhos na faixa etária entre o e I2 anos.

A observação é um método exploratório de pesquisa que busca identificar o comportamento real das pessoas, caracterizando-se como fonte primária de informação e complemento a outros métodos (AAKER; KUMAR; DAY, 2OOI). Malhotra (2OOI), que conceitua esse método como uma pesquisa descritiva, pelo registro sistemático do comportamento das pessoas, destaca que o observador não faz perguntas às pessoas que estão sendo observadas.

Neste estudo, foi realizada uma observação direta (ou pessoal), em que o observador esteve fisicamente presente no supermercado, registrando características de comportamento e fatos. A observação foi não participante, já que a função do observador não era conhecida pelos observados e ele não procurou controlar ou manipular o ambiente ou a situação. A observação com o público alvo, neste caso com as crianças na faixa etária entre o e I2 anos, teve como objetivo principal identificar os fatores que influenciam suas decisões nas compras no supermercado.

Nessa etapa foi realizada cerca de oito horas de observação, nos supermercados da cidade de Caruaru, no dia iI de junho de 2OII. Na segunda fase foi utilizado o questionário que segundo Hair Jr. et al. (2005) é um conjunto predeterminado de perguntas criadas para coletar dados dos respondentes, que neste caso, foram pais com filhos na faixa etária de o a I2 anos. É um instrumento cientificamente desenvolvido para medir características importantes de indivíduos, 
empresas, eventos e outros fenômenos. Uma boa survey exige bons questionários para garantir a precisão dos dados.

O questionário foi elaborado tendo como base a escala de Likert, que é uma escala de mensuração com cinco categorias de respostas, variando de discordo totalmente (número I) a concordo totalmente (número 5), que exige que os participantes indiquem um grau de discordância ou de concordância com cada uma de várias afirmações relacionadas aos objetos de estímulo (MALHOTRA, 20o6). Houve também a realização de um pré-teste com ıo respondentes, com o objetivo de identificar e eliminar problemas potenciais no questionário (MALHOTRA, 20o6), do qual os respondentes não fizeram parte da amostra final, com o objetivo de evitar vieses e de verificar se as respostas conseguidas nos permitiriam alcançar o objetivo da pesquisa.

O questionário aplicado foi do tipo auto-administrado que são frequentemente respondidos sem a presença de um pesquisador. Supõe-se que o respondente tenha conhecimento e motivação para completá-lo sozinho. Esse questionário foi dirigido aos pais, para complementação da primeira etapa.

\section{Tratamento dos Dados Coletados}

Os dados coletados foram analisados a partir da pesquisa de campo realizada para este artigo, através da análise de conteúdo com a ajuda da construção de tabelas e da utilização do programa estatístico SPSS I3.o (Statistical Package for the Social Sciences), através de frequência, que é um valor numérico que representa o número total de observações para cada variável estudada (COLLIS; HUSSEY, 2005), média que é o resultado da soma de um conjunto de valores dividido pelo número de valores presentes na pesquisa (APPOLINÁRIO, 2006), desvio-padrão que corresponde a raiz quadrada da variância, sendo a medida mais importante de dispersão porque usa cada valor nas mesmas unidades dos dados originais e é apresentado junto com a média (COLLIS; HUSSEY, 2005) também foi utilizado na análise a ANOVA, para analisar a variância de um fator e verificar as diferenças entre 
médias de subgrupos (renda familiar) (MALHOTRA, 2006) e por último para testar as hipóteses foi aplicado o coeficiente de correlação $\mathrm{r}$ de Pearson ou correlação momento-produto que é a estatística que resume a intensidade de associações entre duas variáveis, onde vai indicar o grau em que a variação de uma variável está relacionada com outra variável (MALHOTRA, 2006).

\section{Hipóteses}

De acordo com Vergara (2009), hipóteses, ou suposições, são "a antecipação da resposta ao problema". Uma hipótese seria uma afirmação ou proposição não comprovada a respeito de um fator ou fenômeno que é de interesse do pesquisador (MALHOTRA, 2006). As hipóteses frequentemente descrevem eventos sistemáticos que podem ser testados com o uso de dados. Essas vão além das questões de pesquisas, pois são afirmações de relações com o problema proposto. A investigação é realizada de modo que se possa confirmar ou rejeitar a hipótese (MALHOTRA, 20o6; VERGARA, 2009).

Gil (I995) afirma que as hipóteses são elementos vitais em uma pesquisa científica, pois dirigirão todo o trabalho do pesquisador. Porém é importante ressaltar que nem toda pesquisa obrigatoriamente apresentará hipótese. Em alguns casos, não há informações suficientes para a elaboração das hipóteses.

As hipóteses estatísticas são formuladas em formas nula (Ho) e alternativas (HI, H2 etc.). Segundo Malhotra (2006), uma hipótese nula é uma afirmação de que não há qualquer diferença ou efeito, neste caso, se essa for ou não for rejeitada não se faz nenhuma modificação. Uma hipótese alternativa conduz a modificação de opiniões ou de atitudes, assim, ela é o oposto da hipótese nula. Com base na formulação e teste das hipóteses o pesquisador é orientado para a resposta final de sua pesquisa científica.

As hipóteses foram formuladas com base no problema de pesquisa, para servir como orientação da pesquisa de campo, da análise dos dados e da busca dos objetivos propostos no presente artigo: 
Hr: Os pais cederem aos pedidos dos filhos no momento das compras no supermercado relaciona-se com o fato de gastarem mais quando os filhos os acompanham.

H2: As propagandas televisivas influenciam os desejos das crianças e, portanto, elas acabam solicitando aos pais mais os produtos que contenham personagens ou mascotes.

H3: A classe social interfere na decisão dos pais de comprarem ou não o produto solicitado pelos filhos e isso reflete em os pais levarem em conta o preço dos produtos solicitados no momento das compras.

$\mathrm{H}_{4}$ : Os pais levarem seus filhos às compras no supermercado tem uma relação com o fato de acharem isso viável ou não.

\section{Apresentação e análise dos resultados}

Do total dos Io8 respondentes do questionário destinado aos pais, observou-se o seguinte perfil dos mesmos: 8I (75\%) do sexo feminino e 27 (25\%) do sexo masculino; quanto à idade I (9\%) tem entre I6 a 20 anos, II (IO,2\%) têm entre 2I a 25 anos, 34 (3I,5\%) têm entre 26 a 3 O anos, 28 (25,9\%) têm entre 3 I a 35 anos, 28 (259\%) têm entre 36 a 40 anos e $6(5,6 \%)$ têm $4 \mathrm{I}$ anos ou mais; sobre o estado civil I4 (I3\%) são solteiros, $62(57,4 \%)$ são casados, 7 (6,5\%) são divorciados, 9 $(8,3 \%)$ são viúvos e $4(3,7 \%)$ são separadas e I2 (II,I\%) têm uma união estável; em relação a faixa etária dos filhos $22(20,4 \%)$ têm entre o a 3 anos, $40(37 \%)$ têm entre 4 a 6 anos, $24(22,2 \%)$ têm entre 7 a 9 anos e 22 (28,4\%) têm entre Io a I2 anos; quanto ao sexo dos filhos $57\left(5^{2,8 \%}\right)$ são do sexo feminino e $5^{\mathrm{I}}(47,2 \%)$ são do sexo masculino; e em relação à renda familiar (que segundo o IBGE são divididas em cinco classes: classe E para os que ganham até 2 salários mínimos, classe D para os que ganham de 2 a 6 salários mínimos, classe C para os que ganham de 6 a I 5 salários mínimos, classe B para os que ganham de I5 a 3 o salários mínimos e classe A para os que ganham acima de 30 salários mínimos) dos pesquisados 50 (46,3\%) são da 
classe E, $5^{2}(48, \mathrm{I} \%)$ são da classe D, $6(5,6 \%)$ são da classe C, o (o\%) são da classe B e o (o\%) são da classe A.

\section{Variáveis de Observação com as Crianças}

Do total das 24 crianças observadas, percebeu-se que: i2 (50\%) foram do sexo feminino e г2 (50\%) do sexo masculino; quanto a idade 5 (20,8\%) têm entre o a 3 anos, $8(33,3 \%)$ têm entre 4 a 6 anos, $9(37,5 \%)$ têm entre 7 a 9 anos, $2(8,3 \%)$ têm entre IO a I2 anos; em relação ao nível social do supermercado analisado 8 (33,3\%) foram de classe média alta e i6 $(66,7 \%)$ foram de classe média baixa; sobre o que a criança costuma levar em consideração no momento das compras no supermercado notou-se que 8 (33,3\%) levam em consideração personagens, IO (4I,7\%) consideram as marcas dos produtos e $6(25 \%)$ o preço; quanto a criança insistir para que os pais comprem determinado produto observou-se que I4 $\left(5^{8}, 3 \%\right)$ insistem e Io $(4 \mathrm{I}, 7 \%)$ não insistem; em relação aos pais cederem aos pedidos dos filhos I5 $_{(62,5 \%)}$ acabaram cedendo e $9(37,5 \%)$ não cederam; sobre a criança aceita o não como resposta verificou-se que $I_{5}(62,5 \%)$ aceitam e $9(37,5 \%)$ não aceitam; quanto a criança conseguir o produto desejado e ela solicitar outros I5 $(62,5 \%)$ solicitam outros produtos e 9 (37,5\%) não solicitam; em relação a imposição de limites por parte dos pais a criança 2I $(87,5 \%)$ não impuseram limites e $3(\mathrm{I} 2,5 \%)$ limitaram os pedidos das crianças; quanto a liberdade da criança para escolha dos seus próprios produtos $8(33,3 \%)$ tinham liberdade e I6 $(66,7 \%)$ não tinham; sobre a participação ativa da criança no momento das compras no supermercado notou-se que I7 (70,8\%) participam e $7(29,2 \%)$ não participam ativamente e com relação a satisfação da criança após as compras no supermercado verificou-se que 2I $(87,5 \%)$ saem satisfeitas e que $3($ (2, $5 \%$ ) não saem totalmente satisfeitas.

Nessa pesquisa foram analisados supermercados com foco em níveis sociais distintos, um dirigido para classe média alta e outro para a classe média baixa, com o objetivo de correlacionar o comportamento das crianças e dos pais com níveis sociais diferentes. E constatou-se que no supermercado direcionado para o público 
de nível social mais elevado as crianças tinham maior liberdade de escolha e que não eram impostos limites às crianças, em quanto no supermercado direcionado para o nível social mais baixo, as crianças não tinham poder de escolha e eram muitas vezes reprimidas pelos pais quando solicitavam alguns produtos.

\section{Análise das Variáveis quanto aos Fatores Influenciadores do Comportamento}

A Tabela I apresenta os resultados obtidos com os respondentes em relação às variáveis referentes aos fatores influenciadores do comportamento do consumidor infantil no momento das compras no supermercado, e apresenta os dados por meio de média e desvio-padrão. Avaliando o primeiro fator que influencia o comportamento do consumidor, ou seja, o fator cultural, que é representado pelas variáveis I e 2, verifica-se pelas médias 3,5I e 3,78 e desvio-padrão I,3O e I,4O respectivamente que os pais têm o costume de levar seus filhos para fazer compras no supermercado e que os levam por vontade própria e não por outros fatores alheios as suas vontades. Na avaliação do segundo fator, o social, representado pelas variáveis 3 e 4, que apresentam médias 2,83 e 3,I9 e desvio-padrão I,53 e I,58 percebe-se que o convívio familiar ou o grupo de amizades não influencia significativamente as crianças na hora das compras no supermercado, porém a classe social interfere na decisão dos pais de comprar ou não o produto solicitado pelos filhos.

O terceiro fator, que é o fator pessoal, está presente nas variáveis 5 e 6 da Tabela I, com médias de 2,74 e 3,25 e desvio-padrão de I,32 e I,47 mostrando que os pais não cedem sempre aos pedidos dos filhos em relação a compras no supermercado,mas que acham viável levá-los. Finalmente no quarto fator, que é o psicológico, representado pelas variáveis 7 e 8, verifica-se as médias 2,67 e 3,66 e desvios-padrão I,36 e I, 46 respectivamente que apresentam que mesmo com muita insistência por parte dos filhos, os pais não compram o produto solicitado por eles e também mostram que os produtos que contêm personagens ou mascotes são mais solicitados pelas crianças. 
Tabela I- Fatores Influenciadores do Comportamento do Consumidor Infantil

\begin{tabular}{|c|c|c|}
\hline Variável & Média & D.P.* \\
\hline 1. Você sempre leva seu(s) filho(s) às compras no supermercado. & 3,51 & 1,30 \\
\hline $\begin{array}{l}\text { 2. É de espontânea vontade que você leva seu(s) filho(s) às compras no supermercado. } \\
\text { 3. O convívio familiar ou o grupo de amizades de } \operatorname{seu}(\mathrm{s}) \text { filho(s) o(s) influencia(m) na }\end{array}$ & 3,78 & 1,40 \\
\hline hora das compras no supermercado. & 2,83 & 1,53 \\
\hline $\begin{array}{l}\text { 4. Sua classe social interfere na sua decisão de comprar ou não o produto solicitado por } \\
\text { seu(s) filho(s). }\end{array}$ & 3,19 & 1,58 \\
\hline $\begin{array}{l}\text { 5. Você sempre cede aos pedidos do(s) seu(s) filho(s) na hora das compras no } \\
\text { supermercado. }\end{array}$ & 2,74 & 1,32 \\
\hline 6. É viável levar seu(s) filho(s) às compras no supermercado. & 3,25 & 1,47 \\
\hline $\begin{array}{l}\text { 7. Quando há muita insistência por parte do(s) seu(s) filho(s), você acaba comprando o } \\
\text { produto solicitado por ele(s). }\end{array}$ & 2,67 & 1,36 \\
\hline 8. Seu(s) filho(s) solicita $(\mathrm{m})$ mais os produtos que contêm personagens ou mascotes. & 3,66 & 1,46 \\
\hline
\end{tabular}

Fonte: Pesquisa de campo realizada em junho de $20 I I$.

Em síntese, analisando toda a Tabela I, percebe-se que todos os fatores (cultural, social, pessoal e psicológico) influenciam o comportamento do consumidor infantil, porém destacaram-se os fatores culturais como os mais importantes influenciadores do comportamento das crianças, por possuírem duas das maiores médias e dois dos menores desvios-padrão.

\section{Análise das Variáveis quanto ao Mix de Marketing}

Como pode ser visto na Tabela 2, de acordo com a variável 9, que possui média de 3,77 , as propagandas televisivas são importantes influenciadoras no desejo das crianças por produtos específicos, o que é muito importante para o profissional de marketing, pois indica que as crianças mostram interesse pelas propagandas televisivas, porém o desvio-padrão de $\mathrm{I}, 5^{2}$, mostra que não há um consenso sobre isso.

A variável Io, que possui média 4,OO e desvio-padrão I,24, indica que para os pais é importante que o produto adquirido pelos filhos tenha uma boa qualidade, para que eles comprem. Como também a variável II, que tem média 3,74 e desviopadrão I,44, mostra que os pais sempre levam em consideração o preço do produto, porém não tanto quanto a qualidade.

Já a variável I2, com média 3,39 e desvio-padrão I,5I, mostra que os pais gastam mais quando levam seus filhos para fazer compras no supermercado. 
Tabela 2 - Apresentação das Variáveis sobre o Mix de Marketing

\begin{tabular}{lcc}
\hline \multicolumn{1}{c}{ Variável } & Média & D.P.* \\
\hline 9. As propagandas televisivas influenciam os desejos do(s) seu(s) filho(s) por & 3,77 \\
produtos específicos. & 4,00 & 1,52 \\
10. Você sempre leva em conta a qualidade do produto escolhido por seu(s ) fillho(s). & 1,24 \\
11. No momento da opção pelo produto solicitado por seu(s) filho(s), você sempre & 3,74 \\
leva em consideração o preço do produto. & 3,39 \\
12. Você gasta mais quando leva seu(s) filho(s) às compras no supermercado. & 1,44 \\
\hline
\end{tabular}

Fonte: Pesquisa de campo realizada em junho de 20 II.

${ }^{*}$ D.P. $=$ Desvio padrão

E, finalmente, considerando toda a Tabela 2, podemos destacar que os elementos do mix de marketing analisados (boa qualidade, ser bem divulgado e ter um preço acessível), são muito importantes neste segmento, pois foi no mix de marketing que se destacaram as maiores médias da pesquisa em geral.

\section{Apresentação da ANOVA}

A Tabela 3 pondera as avaliações anteriores acerca das características de cada variável em relação aos subgrupos da renda dos respondentes. Para tanto, considerou-se a hipótese nula (Ho) que não existem diferenças estatísticas entre as médias dos subgrupos da renda dos respondentes em relação às variações de cada dimensão sugerida. E, em contra partida, considerou-se a hipótese alternativa (HI) de que existem diferenças estatísticas entre as médias dos referidos subgrupos. Com a utilização da ANOVA, visto que o modelo é não-equilibrado porque os subgrupos da renda familiar têm números diferentes de sujeitos.

Com os resultados obtidos da ANOVA observa-se que existem diferenças significativas entre as médias para cada categoria no que diz respeito à "É de espontânea vontade que você leva seu(s) filho(s) às compras no supermercado" (F= I,9I4; sig. $=$ o,OI), isso pode nos remeter que se os pais levam seus filhos ao supermercado por vontade própria ou não, essa atitude não se refere à renda dos mesmos e sim a eles acharem ser propício ou não levá-los. No caso de "Você sempre cede aos pedidos do(s) seu(s) filho(s) na hora das compras no supermercado" $(\mathrm{F}=$ 2,597; sig.= o,o3), é passível de verificação que os pais com renda menor tendem a 
não ceder aos pedidos dos filhos por não terem condição financeira para tal, já os pais de renda média são mais propensos a cederem aos pedidos dos filhos, enquanto que pais de renda mais elevada não cedem aos pedidos dos filhos por outros fatores como por exemplo um método de educação familiar.

Tabela 3- Avaliações das Características das Variáveis Referentes aos Fatores Influenciadores do Comportamento do Consumidor e o Mix de Marketing de Acordo com os Subgrupos de Renda Familiar

\begin{tabular}{|c|c|c|c|c|c|c|}
\hline \multirow[t]{2}{*}{ Variável } & \multicolumn{2}{|c|}{ Até $\mathbf{R} \$ 1.020,00(n=50)$} & \multicolumn{2}{|c|}{$\begin{array}{l}\text { De R\$1.021,00 até } \\
\text { R\$3.060,00 }(n=52)\end{array}$} & \multicolumn{2}{|c|}{$\begin{array}{l}\text { De R\$3.061,00 até } \\
\text { R\$7.650,00 }(n=6)\end{array}$} \\
\hline & Média & D.P.* & Média & D.P.* & Média & D.P.* \\
\hline 1. Você sempre leva... & 3,52 & 1,249 & 3,54 & 1,335 & 3,17 & 1,602 \\
\hline 2. É de espontânea vontade... & 3,70 & 1,418 & 3,96 & 1,386 & 2,83 & 1,169 \\
\hline 3. Você sempre cede... & 2,46 & 1,358 & 3,04 & 1,220 & 2,50 & 1,643 \\
\hline 4. Quando há muita insistência... & 2,24 & 1,238 & 3,00 & 1,400 & 3,33 & 1,211 \\
\hline 5. As propagandas televisivas.. & 3,68 & 1,544 & 3,88 & 1,464 & 3,50 & 1,975 \\
\hline 6. Seu(s) filho (s) solicita (m).. & 3,30 & 1,488 & 4,00 & 1,299 & 3,67 & 2,066 \\
\hline 7. No momento da opção pelo.. & 3,88 & 1,394 & 3,69 & 1,462 & 3,00 & 1,673 \\
\hline 8. Você sempre leva em conta... & 3,96 & 1,340 & 4,25 & ,926 & 2,17 & 1,472 \\
\hline 9. O convívio familiar ou o grupo... & 2,54 & 1,606 & 3,13 & 1,401 & 2,67 & 1,862 \\
\hline 10. Sua classe social interfere... & 2,66 & 1,611 & 3,79 & 1,289 & 2,33 & 2,066 \\
\hline 11. Você gasta mais quando... & 3,32 & 1,544 & 3,50 & 1,421 & 3,00 & 2,191 \\
\hline 12. É viável levar seu(s) filho(s).. & 3,64 & 1,274 & 2,92 & 1,607 & 2,83 & 1,169 \\
\hline
\end{tabular}

Nota. As médias que estão destacadas são as que apresentam diferenças significativas estatisticamente.

Fonte: Pesquisa de campo realizada em junho de $20 I I$.

* D.P. = Desvio-padrão

Em “Quando há muita insistência por parte do(s) seu(s) filho(s), você acaba comprando o produto solicitado por ele $(\mathrm{s}) "(\mathrm{~F}=5, \mathrm{O} 49$; sig. $=0,05)$, infere-se que comprar o produto por causa da insistência dos filhos varia de acordo com a renda,os de renda mais baixa cedem menos e os de renda mais alta têm a tendência de ceder mais quando há insistência por parte dos filhos. Já em "Seu(s) filho(s) solicita(m) mais os produtos que contêm personagens ou mascotes" $(\mathrm{F}=3, \mathrm{O} 38$; sig. $=0,05)$, com esse resultado entende-se que as crianças de renda média e alta solicitam mais os produtos que contêm personagens ou mascotes de que as de renda inferior, o que pode ser um indício de que estas crianças teriam outras prioridades acima daquelas, porém todas tendem a solicitar mais esses tipos de produtos.

Em "No momento da opção pelo produto solicitado por seu(s) filho(s),você sempre leva em consideração o preço do produto" (F= I,O54; sig:= o,o3) nos revela

\section{Revista Administração em Diálogo} ISSN 2178-0080

Programa de Estudos Pós-Graduados em Administração Pontifícia Universidade Católica de São Paulo 
que quanto maior o poder aquisitivo dos pais, menos eles se preocupam com o preço do produto, mas em geral todos tendem a considerar o preço do produto. E em "Você sempre leva em conta a qualidade do produto escolhido por seu(s) filho(s)" ( $\mathrm{F}=8,656$; sig.= ooo), foi visto que os pais de maior renda não analisam tanto a qualidade do produto, enquanto que a qualidade do produto é fundamental para os pais de classe média e baixa. Em "O convívio familiar ou o grupo de amizades de seu(s) filho(s) o(s) influencia na hora das compras no supermercado" $(\mathrm{F}=\mathrm{I}, 979$; sig. $=$ o,oI $)$, percebe-se que mesmo sem um consenso entre os pais de rendas diferentes, em geral, o convívio familiar ou o grupo de amizades não tem tanta influência sobre os filhos, independente do nível social.

Em "Sua classe social interfere na sua decisão de comprar ou não o produto solicitado por seu(s) filho(s)" $(\mathrm{F}=8,345$; sig.= ooo $)$, revela que os pais discordam em relação à afirmação de que a classe social interfere na decisão de comprar ou não o produto solicitado pelos filhos, o que pode remeter ao fato de que há outros fatores que interferem nessa decisão e não a classe social, como por exemplo impor limites aos filhos. Em "É viável levar seu(s) filho(s) às compras no supermercado" $(\mathrm{F}=3,420$; sig. $=0,03)$, houve uma relação com a renda familiar, pois os pais com renda menor acham interessante levar seus filhos às compras no supermercado, enquanto que os de renda maior não acham que seja conveniente levá-los, o que mostra que estão mais preocupados em não ter aborrecimentos na hora das compras, como por exemplo, ter uma certa insistência por parte dos filhos e eles acabarem cedendo aos seus pedidos. Dessa forma, o teste rejeita a hipótese nula (Ho) dessas variáveis, provando estatisticamente que há diferença significativa entre os subgrupos da renda familiar em relação às variáveis listadas no parágrafo anterior.

Entretanto, constatou-se que para 3 das I2 variáveis constantes na Tabela 3 não foi possível rejeitar a hipótese nula (Ho) por não apresentarem diferença estatística significativa, são elas: "Você sempre leva seu(s) filho(s) às compras no supermercado" $(\mathrm{F}=22 \mathrm{O}$; sig. $=0,8 \mathrm{I} 3)$, em que demonstra que independente da renda familiar, os pais costumam levar seus filhos às compras no supermercado, o 
que demonstra que os pais querem que as crianças participem e aprendam a ter responsabilidades; e “As propagandas televisivas influenciam os desejos do(s) seu(s) filho(s) por produtos específicos" $\left(\mathrm{F}=3^{26}\right.$; sig. $\left.=0,723\right)$, mostra que os pais concordam que as propagandas televisivas têm um grande poder influenciador sobre seus filhos, sendo eles de renda baixa, média ou alta; e em "Você gasta mais quando leva seu(s) filho(s) às compras no supermercado" $(\mathrm{F}=385$; sig. $=0,682)$, os pais chegaram a um acordo que levando seus filhos ao supermercado há uma probabilidade maior de gastarem mais, por ser difícil não cederem aos filhos no momento das compras.

\section{Testes das Hipóteses por meio da Correlação r de Pearson}

Para melhor compreensão do grau de associação entre as hipóteses citadas anteriormente neste estudo, foi feita a correlação (r) de Pearson de produtomomento. Os resultados mostram que em Hi (Os pais cederem aos pedidos dos filhos no momento das compras no supermercado relaciona-se com o fato de gastarem mais quando os filhos os acompanham), não houve correlação das variáveis $(\mathrm{r}=$ o,I7I $)$, ou seja, foi aceita Ho. Esse resultado nos remete ao entendimento de que se cederem ou não aos pedidos dos filhos, os pais não gastam mais por esse motivo;

Já em $\mathrm{H}_{2}$ (As propagandas televisivas influenciam os desejos das crianças e, portanto, elas acabam solicitando aos pais mais os produtos que contenham personagens ou mascotes), foi rejeitada Ho, pois $\mathrm{H}_{2}$ apresenta uma correlação significativa de $(\mathrm{r}=0,574 ; \mathrm{p} \leq \mathrm{O}, \mathrm{OI})$, o que mostra que como as crianças estão atentas às propagandas televisivas e são influenciadas por elas, esse público solicita mais os produtos que contêm personagens ou mascotes, que geralmente são identificados nas propagandas;

Agora em H3 (A classe social interfere na decisão dos pais de comprarem ou não o produto solicitado pelos filhos e isso reflete em os pais levarem em conta o preço dos produtos solicitados no momento das compras.), foi aceita Ho, pois não há uma correlação significativa existente $(\mathrm{r}=0,064)$, que conduz ao entendimento 
de que o nível social nada tem a ver com os pais analisarem o preço do produto, analisar o preço não está ligado ao poder financeiro dos pais e sim ao seu modo de ser, seu comportamento, sua cultura; e

Já em $\mathrm{H}_{4}$ (Os pais levarem seus filhos às compras no supermercado tem uma relação com o fato de acharem isso viável ou não) foi rejeitada a Ho, pois $\mathrm{H}_{4}$ expõe uma correlação de $(r=0,489 ; p \leq 0, O I)$, esta hipótese nos leva a conclusão de que, se os pais levam seus filhos é porque acham viável e se não o fazem é porque não concordam que vale a pena levá-los.

\section{Considerações Finais}

Na análise dos fatores que influenciam o comportamento do público infantil no setor de compras no supermercado, conclui-se que os fatores sociais, culturais, pessoais e psicológicos têm relevância na escolha desse público, porém infere-se que os fatores culturais e sociais são os de maior importância na decisão das crianças.

Verificou-se também que os componentes do mix de marketing que foram abordados por esta pesquisa (boa qualidade, ser bem divulgado e ter um preço acessível), revelaram-se como influenciadores de grande potencial na atitude dos filhos e no comportamento de compra dos pais, atingindo as maiores médias de toda pesquisa. É importante destacar que entre os motivos que levam as crianças a escolherem determinado produto o de maior relevância foi à marca do produto, em seguida estão os produtos que contêm personagens e mascotes.

Constatou-se que das crianças observadas, a maioria insiste para que os pais comprem determinado produto, e a maioria destes cede quando há muita insistência por parte dos filhos, o que comprova que as crianças têm bastante influência sobre os pais no momento das compras. Também foi visto que mesmo obtendo aquele produto desejado, a maioria dos filhos solicita outros produtos, e a grande maioria dos pais não impõe limites a seus filhos. 
Um dado essencial observado foi que uma grande maioria participa ativamente das compras no supermercado, porém não têm liberdade de escolha. E o dado que talvez seja o mais importante para a pesquisa, é que $87,5 \%$ das crianças saem satisfeitas depois de fazer as compras no supermercado, e é interessante para o marketing que elas saiam satisfeitas, pois provavelmente estão adquirindo o que querem, e comprovadamente desejam os mais divulgados.

Testar as hipóteses também foi fundamental para este estudo, porque apresentou quais variáveis estão interligadas no momento das compras, e saber dessa correlação é muito importante para o profissional de marketing, pois ele pode focar em uma variável para atingir a outra. Assim, relativo às hipóteses, percebeu-se que as crianças são influenciadas pelas propagandas televisivas e estas fazem com que elas solicitem mais os produtos que contêm personagens ou mascotes, e também que os pais levam seus filhos às compras no supermercado porque acham viável levá-los e não por outros motivos alheios às suas vontades. Também percebeu-se na análise da hipóteses que o fato de os pais gastarem mais, não tem relação com o fato de cederem aos apelos de seus filhos e que os pais quando levam em consideração o preço do produto, não é por sua classe social e sim pelo seu modo de ser, sua cultura.

Assim, conclui-se que é de fundamental importância que os profissionais desta área tenham um conhecimento aprofundado sobre os fatores que influenciam as crianças no momento das compras, pois, todos os elementos analisados neste estudo, alguns mais relevantes que outros, mostraram que são de grande influência sobre os comportamentos das crianças e dos pais em relação às compras no supermercado, e que o marketing tem grande poder para atingir o público infantil, e consequentemente, seus pais.

Para esse estudou foi realizada uma revisão bibliográfica, como a pesquisa bibliográfica é o estudo em material acessível ao público em geral, observou-se uma escassez de material com relação ao comportamento do consumidor infantil, o que dificultou a pesquisa nessa área. Houve também certa dificuldade quanto à 
realização da pesquisa por ela ser dirigida ao público infantil, pois com as crianças é mais difícil obter resultados. Como recomendação para futuras pesquisas sugere-se que seja feito um estudo qualitativo com intuito de confrontar os resultados encontrados por esta pesquisa quantitativa, e também como forma de expandir os conceitos dessa área ainda pouco explorada pelos pesquisadores.

\section{Referèncias}

ASSOCIAÇÃO Brasileira de Marketing \& Negócios. A Imagem da Area de Marketing no Brasil. Disponível em $<$ http://www.abmn.com.br/menu/index.asp $>$. Acesso em 20 de maio de $20 I I$.

AAKER, D. A.; KUMAR, V.; DAY, G. S. Pesquisa de Marketing. São Paulo. Editora Atlas, 200 . APPOLINÁRIO, F. Metodologia da ciência: filosofia e prática da pesquisa. São Paulo: Pioneira Thomson Learning, 2006.

BOONE, L. E.; KURTZ, D. L. Contemporary Marketing. Io ed. Orlando: Harcourt College Publishers, 2OOI.

BRËE, J. Los niños, el consumo y el marketing. Barcelona: Ediciones Paidós, I995.

CHURCHILL JR, G. A.; PETER, J. P. Marketing: criando valor para os clientes. 2 ed. São Paulo: Saraiva, 200o.

COBRA, M. Administração de Marketing. São Paulo: Atlas, 2002.

COLLIS, J.; HUSSEY, R. Pesquisa em administração: um guia prático para alunos de graduação e pós-graduação. 2. ed. Porto Alegre: Bookman, 2005.

DAMATTA, R. Relativizando: uma introdução à antropologia. Petrópolis: Vozes, I98I.

DERBAIX, C. Lés réactions dés consommateurs à la communication publicitaire et La hiérarchie dés effets. Revue Français du Marketing, nº 58, p.7-26, 1975.

DERBAIX, C. L'enfant, la communication publicitaire et la hiérarchie dés effets. Revue Français du Marketing, 1982.

ENGEL, J. F.; BLACKWELL, R. D.; MINIARD, P. W. Comportamento do consumidor. 8 ed. Rio de Janeiro: Livros Técnicos e Científicos, 2000.

GARDNER, H. A criança pré-escolar: como pensa e como a escola pode ensiná-la. Porto Alegre: Artes Médias, I994.

GIACOMINI FILHO, G. Consumidorversus Propaganda. São Paulo: Summus, I99I.

GIL, A. C. Métodos e técnicas de pesquisa social. 4 ed. São Paulo: Atlas, I995. 
GORN, G. J.; GOLDBERG, M. E. Children's responses to repetitive television commercials. Journalof Consumer Research, 1980.

HAIR Jr., J. F. et al. Fundamentos de métodos de pesquisa em administração. Porto Alegre: Bookman, 2005.

HOLBROOK, M. B. What Is Consumer Research? Journal of Consumer Research, v. I4, p. I28I32, June 1987 .

JUNG, C. Tipos psicológicos. Rio de Janeiro: Zahar, I974.

KARSAKLIAN, E. Comportamento do consumidor. São Paulo: Atlas, 2000.

KOTLER, P. Administração de Marketing. Io. ed. São Paulo: Pearson Prentice Hall, 2000.

KOTLER, P.; KELLER, K. L. Administração de marketing. I2. ed. São Paulo: Pearson Prentice Hall, 2006.

LE BIGOT, J. Y. The economic influence of young people in France... its philosophical implications. Esomar - children and young people. Vienna, I980.

LINNEMAN, R.; STANTON JR, J. Marketing de Nichos. São Paulo: McGraw, I993.

MACIEL, M. E. S. Marcas. In: Nós, os gaúchos. 2 ed. Porto Alegre: UFRGS. 1996.

MALHOTRA, N. K. Pesquisa em Marketing: uma orientação aplicada. Porto Alegre: Bookman, 2 OOI.

Pesquisa em Marketing: uma orientação aplicada. 4. ed. Porto Alegre: Bookman, 2006.

MCCARTHY, J. Basic Marketing: A Global Managerial Approach. Richard Irwin, I996.

. Basic Marketing Approach. Homework, IL, Irwin, I96o.

MCNEAL, J. U. The child consumer: a new market. Journal of Retailing. v. 45, n. 2, I969.

. Kids as costumers: a handbook of marketing to children. New York: Lexington books, I992.

. Children as Consumers of Commercial and Social Products. Marketing health to kids 8 to I2 years of age. Washington, 2000.

MOSCHIS, G. P.; MOORE, R. L. An analysis of the acquisition of some consumer competencies among adolescents. The Journal of Consumer Affairs. v. I2, n. 2, p. 277-29I, I978.

PETER, J. P.; OLSON, J. C. Consumer behavior and marketing strategy • 5. ed. New York: Irwin McGraw-Hill, I999.

PIRES, C. Crianças estão mais exigentes para comprar. São Paulo: Folha de São Paulo, o4 de dezembro de 2005 . 
PORTER, M. Estratégias Competitivas. Rio de Janeiro: Campus, I99I.

RABELO, A.; CARDOSO, A. Marketing Infantil- Como Conquistar a Criança como

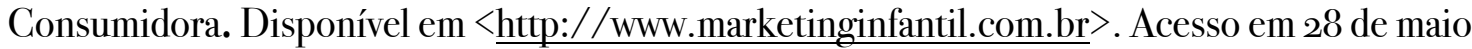
de 2OII.

RICCA, D. Administração e marketing para pequenas e médias empresas de varejo. São Paulo: CLA Cultural, 2005.

RICHERS, R. O enigmático mais indispensável consumidor: teoria e prática. Revista da Administração, jul./set. de I984.

SAMPIERI, R. H.; COLLADO, C. F.; LUCIO, P. B. Metodologia de pesquisa . 3 ed. São Paulo: McGraw-Hill, 2006.

SCHIFFMAN, L. G.; KANUK, L. L. Comportamento do consumidor. 6 ed. Rio de Janeiro: LTC, 2000 .

SERRALVO, F. A.; IGNÁCIO C. P. O processo de escolha de marcas no mercado de produtos alimentícios. In: Anais do Encontro Nacional dos Programas de Pós-Graduação em Administração, XXIX EnAnpad, p. I- I7. Brasília: ANPAD, 2005.

SHETH, J.; MITTAL, B.; NEWMAN, B. Comportamento do Cliente: indo além do comportamento do consumidor. São Paulo. Atlas, 2OOI.

SOBRAL, F.; PECI, A. Administração: Teoria e Prática no Contexto Brasileiro. i ed. São Paulo: Prentice Hall, 2008.

TOLEDO, G. L.; NAKAGAWA, M. H.; YAMASHITA, S. S. O Composto de marketing no contexto estratégico da Internet. Revista de Administração Mackenzie. São Paulo, vol. 3, n I, 2002.

UNDERHILL, P. Vamos às compras: a ciência do consumo. São Paulo: Campus, I999.

VERGARA, S. C. Projetos e relatórios de pesquisa em administração. Io ed. São Paulo: Atlas, 2009.

WHITE, O. M. Considerações gerais sobre o ato de compra por parte do pré-adolescente.

Dissertação (Mestrado em Administração). FEA- USP, ı997. 